\title{
Validity and reliability of the Brazilian version of the Patient Dignity Inventory (PDI - Br)*
}

\author{
Suzana Cristina Teixeira Donato ${ }^{1}$ \\ (D) https://orcid.org/0000-0001-8876-2816 \\ Toshio Chiba ${ }^{2}$ \\ (D) https://orcid.org/0000-0003-2596-7966 \\ Ricardo Tavares de Carvalho² \\ (1D) https://orcid.org/0000-0003-0841-2985 \\ Marina de Góes Salvetti ${ }^{1}$ \\ (D) https://orcid.org/0000-0002-4274-8709
}

Objective: to perform the psychometric validation of the Brazilian version of the Patient Dignity Inventory (PDI - Br) in patients with advanced diseases in palliative care. Method: a methodological study to verify the psychometric properties of the Patient Dignity Inventory (PDI - $\mathrm{Br}$ ) instrument, through validity and reliability tests. Results: the exploratory factor analysis showed a factorial solution with three factors, responsible for $40.9 \%$ of the explained variance, with adequate internal consistency for the Presence of Symptoms $(a=0.859)$, Dependence $(a=0.871)$, and Existential Suffering $(a=0.759)$ domains. The test-retest was performed and indicated moderate to strong correlations. Convergent validity demonstrated a positive correlation between the Presence of Symptoms and the sadness $(r=0.443)$ and anxiety $(r=0.464)$ variables. Weak negative correlations were observed between the PDI - Br domains and functionality, spiritual well-being and quality of life. Conclusion: composed of three domains and 25 items, the PDI - $\mathrm{Br}$ instrument presented satisfactory psychometric properties for its use in our environment, through the evidence of validity and reliability.

Descriptors: Neoplasms; Palliative Care; Validation Study; Psychometrics; Translating; Surveys and Questionnaires.

\section{How to cite this article}

Donato SCT, Chiba T, Carvalho RT, Salvetti MG. Validity and reliability of the Brazilian version of the Patient Dignity Inventory (PDI - Br). Rev. Latino-Am. Enfermagem. 2021;29:e3371. [Access † — _ ; Available in: DOI: http://dx.doi.org/10.1590/1518-8345.4015.3371. month day year 


\section{Introduction}

The progressive aging of the population shows that people are living longer, but with a high prevalence of chronic diseases, neoplasms or dementia(1-2); consequently, their quality of life decreases. According to the Brazilian Institute of Geography and Statistics (Instituto Brasileiro de Geografia e Estatística, IBGE, in Portuguese), in 2050 the population over 60 will be 2 billion people and 25\% of them will be over $65^{(3)}$. Neoplasms also represent a public health problem and Brazil is expected to have 625,000 new cases per year from 2020 to $2022^{(4)}$.

However, the increase in life expectancy has not been accompanied by a better quality of life in the phenomenon of aging and illness. Technological advances and the variety of therapies available lead to a constant search for the cure of diseases, leaving interventions that focus on the dignified end of life in a second place(5).

Differentiating itself from curative medicine, the palliative care approach is a type of assistance that proposes multifaceted care, with the management of physical, social, emotional, and spiritual symptoms for patients facing advanced life-threatening diseases(5)

In the context of palliative care, patients can experience situations that affect their perception or sense of dignity, which can be defined as a value, from which the person is perceived by the world and by himself/herself as a valuable and respectful human being who keeps its essence intact, even when facing the physical degradation caused by different circumstances ${ }^{(6)}$.

The literature shows that the sensation of loss of dignity has been associated with an absence of the will to live, indicating a strong connection with depression, lack of hope, and expression of an interest in anticipating death ${ }^{(7)}$. Thus, the investigation of the sense or perception of dignity in the scope of palliative care has been gaining prominence in the health area.

A Brazilian study investigated the concept of dignity of patients in palliative care and showed that both health professionals and caregivers can influence self-perception of dignity. Being a "correct" person, maintaining autonomy and being cared for with respect were the elements that positively influenced the perception of dignity; on the other hand, urban violence and the lack of public accessibility policies had negative influences ${ }^{(8)}$.

Physician Harvey Max Chochinov from Canada is one of the main researchers in this area and proposed the Dignity Model, with the purpose of establishing the association between dignity and psychosocial factors in patients in an advanced stage of an incurable disease ${ }^{(9-10)}$. For Chochinov, maintaining dignity allows patients in palliative care to continue performing their usual roles ${ }^{(9-10)}$.

Based on the Theoretical Dignity Model, Chochinov proposed an instrument composed of 25 items distributed in five domains, called the Patient Dignity Inventory (PDI), in order to identify the problems associated with the loss of dignity ${ }^{(9-10)}$

The Dignity Inventory proposed by Chochinov was translated, adapted and validated in Germany, Spain, Italy, Portugal and Greece(11-15). So far, in Brazil there is still no single questionnaire that identifies the problems related to dignity for patients in palliative care, but there is a growing demand for this type of care.

Investigating the concept of dignity in patients in palliative care can contribute to direct the focus of care, in addition to allowing for the evaluation of interventions with the potential to improve the sense of dignity of these patients ${ }^{(2)}$.

Thus, the aim of this study was to perform the psychometric validation of the Brazilian version of the Patient Dignity Inventory (PDI - $\mathrm{Br}$ ) in patients with advanced diseases in palliative care.

\section{Method}

A methodological study to verify the psychometric properties of the Patient Dignity Inventory (PDI - $\mathrm{Br}$ ) instrument, based on validity and reliability tests of the measurement instrument.

The study was set up in outpatient clinics in Palliative Care at the Cancer Institute of the State of São Paulo (Instituto do Câncer do Estado de São Paulo, ICESP, in Portuguese) and at the Clinical Hospital of the Medical School of the University of São Paulo (Hospital das Clínicas da Faculdade de Medicina da Universidade de São Paulo, HC-FMUSP, in Portuguese).

The data collection process was approved by the Ethics Committees of the Nursing School at the University of São Paulo and of co-participating institutions, under opinion No. 2,490,660. In addition, the study was carried out with the assistance of the Coordination for the Improvement of Higher Level Personnel (Coordenação de Aperfeiçoamento de Pessoal de Nível Superior, CAPES, in Portuguese) - Brazil, Code 001. The psychometric validation process of the Patient Dignity Inventory was authorized by Canadian psychiatrist Harvey Max Chochinov, author of the original instrument. 
For selecting the sample, the non-probabilistic sampling technique was chosen for convenience. Men and women in advanced stages of incurable diseases and in palliative care, assisted in the outpatient clinics selected for the study, were invited to participate. Those who met the criteria of a minimum age of 18 years old, maintained cognitive ability (patients without evidence of delirium or dementia) and preserved verbal communication were included in the study.

The data collection process was carried out from April to June 2018. The active search for patients occurred between consultations with the palliative care team. The patients who accepted the approach signed the Free and Informed Consent Form and answered a questionnaire to identify the sociodemographic and clinical situation.

Scales were also applied to assess symptoms and quality of life. The Brazilian version of the Hospital Anxiety and Depression Scale (HADS) was used to assess anxiety and depression. The HADS scale has 14 items divided into two subscales, with scores varying from 0 to 21; scores between 0 and 10 in each subscale indicate absence of symptoms or mild changes and scores between 11 and 21 indicate moderate to severe changes $^{(16)}$. The Brazilian version of the Edmonton Symptom Assessment System (ESAS - Br) was used to assess the intensity of the symptoms: pain, fatigue, nausea, depression, anxiety, drowsiness, appetite, well-being, dyspnea and sleep. Each symptom was assessed from 0 to $10^{(17)}$.

Two items from the Brazilian version of the European Organization for Research and Treatment of Cancer Quality of Life Questionnaire Core 30 (EORTCQLQ-C30) scale were used to assess overall selfperception of health and quality of life. The scores of these items vary from 1 to 7, with 1 being very poor health and quality of life and 7, excellent ${ }^{(18)}$.

The Brazilian version of the Functional Assessment of Chronic Illness Therapy-Spiritual Well-Being (FACITsp 12) scale was used to assess spiritual well-being by means of two subscales: "meaning/peace" and "faith", in which the higher score, the higher the patients> spiritual well-being ${ }^{(19)}$.

The Karnofsky Performance Scale (KPS) was used to assess the functional capacity of the patients, with a score of 100 to 0 , with 100 being preserved functional capacity and 0 representing a patient in the process of death ${ }^{(20)}$, in addition to the translated and adapted version of the Patient Dignity Inventory (PDI - Br).

Construct validity was performed by exploratory factor analysis, which verifies correlations between several variables, grouping them into a set of common latent dimensions, the factors, domains or dimensions(21-24). For the adequacy of the data in the factor analysis, the Kaiser-Meyer-Olkin (KMO) coefficient was used, for which the literature indicates that values above 0.80 are acceptable ${ }^{(24)}$.

The exploratory factor analysis was performed with the Statistical Package for Social Science (SPSS) statistical software, version 20.0 for Windows, through the latent structure of the relations, by the main components. The factor extraction technique was the latent root, for which eigenvalues greater than 1 are significant. The method of oblique rotation (oblimin) of the correlation matrix was used to achieve theoretically significant factors or constructs(24).

By means of concurrent validity, the accuracy of an instrument is verified, contrasting it with a gold standard or an external criterion. This type of verification is divided into two types: convergent (when there is a correlation with the criterion) and divergent (when there is no correlation with the criterion) ${ }^{(25)}$. Concurrent validity was analyzed using Pearson's correlation coefficient, a numerical measure that verifies the relationship between two variables. It ranges from 0 to 1 , either positive or negative and the closer to 1 , the stronger the correlation ${ }^{(24)}$.

In Brazil, until now, there is no model of instrument that quantifies self-perception of dignity. Based on the PDI validation carried out in Germany, Italy, Canada, and Spain ${ }^{(11-14)}$ and according to the literature recommendation, other scales were applied to the patients in association with the Patient Dignity Inventory (PDI), for the analysis of the correspondence of the phenomenon of dignity with external criteria.

For the test of association between dignity and physical symptoms, the Edmonton Symptom Assessment System (ESAS-Br) ${ }^{(17)}$ and the Hospital Anxiety and Depression Scale (HADS)(16) were used. The established assumption was that the loss of dignity has a positive correlation with depression, anxiety, and physical symptoms.

The assumption was also made that the loss of dignity is negatively correlated with functional capacity, spirituality, and quality of life. In order to assess the association between loss of dignity and decreased functional capacity, the Karnofsky Performance Scale(20), the FACIT-sp 12 scale(19) $^{(19}$ and the two items on quality of life of the QLQ-C30 were used(18).

The internal consistency tools were used to assess reliability, using Cronbach's a and test-retest. Internal consistency estimates the isonomy of the items, 
indicating whether the items on the scale measure the same characteristic and, when they do, they are inclined to demonstrate a good correlation with each other ${ }^{(24)}$. The analysis of the $a$ value also contributes to the conformation of the items, to the resolution of sustaining their permanence or the removal(14).

The conjecture of reliability by the test-retest is based on establishing the association of the scores achieved on the same instrument by the same people at two different times and the expectation is that the scores achieved show an association (23-24). In the study, the PDI - $\mathrm{Br}$ was used for patients in the consultation following the first approach.

\section{Results}

In total, 135 patients were analyzed, followed-up at the ICESP (61.5\%) and at the HC-FMUSP (38.5\%) and were approached on average in the $4^{\text {th }}$ consultation; their mean age was 65 years old, with a mean schooling of 5.9 years, and most of them were retired (68.2\%).

Neoplasms were predominant, accounting for $68.2 \%$ of the presentations, followed by diseases of the respiratory system $(11.8 \%)$, cardiovascular diseases $(6.7 \%)$, and neurological diseases $(4.4 \%)$, as shown in Table 1.

The Kaiser-Meyer-Olkin (KMO) coefficient was 0.84 , showing an adequate conformation of the sample to perform factor analysis. Only items 11, 16 and 17 had lower factor loads than those indicated in the literature.

The results of the exploratory factor analysis were organized in a solution of 3 factors, or domains, for the PDI - Br. The eigenvalues found for the domains were 3.70 (A1), 3.33 (A2), and 3.19 (A3). The three factors together are responsible for explaining $40.9 \%$ of the total variance (Table 2 ).

Table 1 - Identification of the patients' sociodemographic and clinical characteristics. São Paulo, SP, Brazil, 2018

\begin{tabular}{|c|c|c|c|}
\hline \multicolumn{4}{|c|}{ Qualitative variables $(n=135)$} \\
\hline & n (\%) & & n (\%) \\
\hline Gender & \multicolumn{2}{|r|}{ Marital status } & \\
\hline Male & $74(54.8)$ & Has a partner & $71(52.6)$ \\
\hline Female & $61(45.2)$ & No partner & $64(47.4)$ \\
\hline Religion & \multicolumn{2}{|r|}{ Work } & \\
\hline Catholic & $76(56.3)$ & Retired & $92(68.2)$ \\
\hline Evangelical & $43(31.9)$ & IIIness benefit & $18(13.3)$ \\
\hline Others & $6(4.4)$ & Unemployed & $13(9.6)$ \\
\hline No religion & $3(2.2)$ & Pensioner & $11(8.2)$ \\
\hline No information & $7(5.2)$ & No information & $1(0.7)$ \\
\hline \multicolumn{4}{|l|}{ Diagnosis } \\
\hline Neoplasms & $92(68.2)$ & & \\
\hline Respiratory system diseases & $16(11.8)$ & & \\
\hline Cardiovascular system diseases & $9(6.7)$ & & \\
\hline Neurological diseases & $6(4.4)$ & & \\
\hline Chronic renal failure & $3(2.2)$ & & \\
\hline Others* & $9(6.7)$ & & \\
\hline Quantitative variables $(n=135)$ & & Mean (SP) & Median \\
\hline Functionality (Karnofsky) & & $66.4(16.6)$ & 60 \\
\hline Age (years old) & & $65.0(16.9)$ & 66 \\
\hline Schooling (years) & & $5.96(4.7)$ & 5 \\
\hline Income $(\mathrm{MW})^{\dagger}$ & & $1.53(1.2)$ & 1 \\
\hline Time of diagnosis (months) & & $75.4(82.7)$ & 39.5 \\
\hline
\end{tabular}

${ }^{*}$ Skin $(1.5 \%)$, hematological $(1.5 \%)$, liver $(1.5 \%)$, and rheumatic $(0.7 \%)$ diseases, and congenital malformation $(1.5 \%)$; ${ }^{+} \mathrm{MW}=\mathrm{Minimum}$ wage in Brazil, in $2018=\mathrm{R} \$ 954.00$ 
Table 2 - Correlation matrix between the items and factors/domains through factor analysis. São Paulo, SP, Brazil, 2018

\begin{tabular}{|c|c|c|c|}
\hline \multirow[t]{2}{*}{ Items } & \multicolumn{3}{|c|}{ Domains } \\
\hline & PA1 & PA2 & PA3 \\
\hline PDI 8 & 0.782 & 0.043 & -0.104 \\
\hline PDI 7 & 0.773 & 0.048 & 0.009 \\
\hline PDI 6 & 0.653 & 0.051 & 0.031 \\
\hline PDI 5 & 0.478 & 0.221 & 0.118 \\
\hline PDI 24 & 0.472 & -0.069 & 0.374 \\
\hline PDI 4 & 0.395 & 0.214 & 0.069 \\
\hline PDI 3 & 0.388 & 0.326 & -0.113 \\
\hline PDI 19 & 0.362 & 0.031 & 0.311 \\
\hline PDI 9 & 0.356 & -0.017 & 0.273 \\
\hline PDI 11 & 0.284 & 0.231 & 0.200 \\
\hline PDI 16 & 0.277 & 0.167 & 0.177 \\
\hline PDI 2 & -0.028 & 0.922 & -0.008 \\
\hline PDI 1 & -0.003 & 0.874 & -0.017 \\
\hline PDI 10 & 0.112 & 0.636 & 0.118 \\
\hline PDI 20 & 0.175 & 0.539 & 0.175 \\
\hline PDI 18 & 0.213 & 0.512 & -0.008 \\
\hline PDI 25 & -0.136 & 0.119 & 0.788 \\
\hline PDI 14 & 0.283 & -0.173 & 0.610 \\
\hline PDI 23 & 0.123 & -0.022 & 0.588 \\
\hline PDI 21 & -0.087 & 0.122 & 0.554 \\
\hline PDI 12 & -0.026 & 0.153 & 0.537 \\
\hline PDI 22 & -0.119 & 0.032 & 0.372 \\
\hline PDI 13 & 0.086 & -0.160 & 0.336 \\
\hline PDI 15 & 0.245 & -0.069 & 0.307 \\
\hline PDI 17 & 0.168 & 0.012 & 0.260 \\
\hline
\end{tabular}

To validate the composition of the PDI - $\mathrm{Br}$ in three factors/domains, correlations between the domains were performed, in pairs. The correlations between the $A 1$ and $A 2$ domains $(r=0.433)$ and between $A 1$ and $A 3$ (0.430) were classified as moderate. The correlation between the $A 2$ and $A 3$ domains was weak (0.285).

To obtain the reliability of the PDI - $\mathrm{Br}$, a testretest was performed with 32 patients approached at two different times, with a mean time span of 31.6 days (SD 11.3). In addition, in the analysis of internal consistency the correlations between items in the three domains detected in the exploratory factor analysis were identified for the reliability of the instrument, described in Table 3.
Table 3 - Internal consistency analysis (Cronbach's a) of the Patient Dignity Inventory (PDI - Br). São Paulo, SP, Brazil, 2018

\begin{tabular}{|c|c|c|c|}
\hline Domain $/ \alpha^{*}$ & Items & $\begin{array}{l}\text { Correlation with } \\
\text { the other items }\end{array}$ & $\begin{array}{l}\alpha \text { value of the } \\
\text { domain if the } \\
\text { item is excluded }\end{array}$ \\
\hline \multirow{11}{*}{$\begin{array}{c}\mathrm{A} 1 \\
(\alpha=0.859)\end{array}$} & 3 & 0.442 & 0.854 \\
\hline & 4 & 0.538 & 0.848 \\
\hline & 5 & 0.633 & 0.840 \\
\hline & 6 & 0.651 & 0.839 \\
\hline & 7 & 0.705 & 0.834 \\
\hline & 8 & 0.631 & 0.840 \\
\hline & 9 & 0.449 & 0.854 \\
\hline & 11 & 0.496 & 0.851 \\
\hline & 16 & 0.439 & 0.855 \\
\hline & 19 & 0.477 & 0.852 \\
\hline & 24 & 0.572 & 0.845 \\
\hline \multirow{5}{*}{$\begin{array}{c}\mathrm{A} 2 \\
(\alpha=0.871)\end{array}$} & 1 & 0.754 & 0.829 \\
\hline & 2 & 0.789 & 0.820 \\
\hline & 10 & 0.708 & 0.841 \\
\hline & 18 & 0.572 & 0.874 \\
\hline & 20 & 0.666 & 0.851 \\
\hline \multirow{9}{*}{$\begin{array}{c}\mathrm{A} 3 \\
(\alpha=0.759)\end{array}$} & 12 & 0.508 & 0.726 \\
\hline & 13 & 0.317 & 0.754 \\
\hline & 14 & 0.613 & 0.705 \\
\hline & 15 & 0.398 & 0.743 \\
\hline & 17 & 0.313 & 0.762 \\
\hline & 21 & 0.424 & 0.740 \\
\hline & 22 & 0.289 & 0.758 \\
\hline & 23 & 0.507 & 0.725 \\
\hline & 25 & 0.619 & 0.709 \\
\hline
\end{tabular}

${ }^{*}$ Cronbach's a

All the items in the $\mathrm{A} 1$ domain presented moderate to strong correlations, as well as the items in the A2 domain. The increase provided in a by the removal of item 18 from the $A 2$ domain was 0.871 to 0.874 . Removing item 17 from the $A 3$ domain increased a from 0.759 to 0.762 (Table 3).

The correlation analysis of the retest for items 2, 5 , $13,14,15,16,17$, and 18 was strong and significant. Items 1, 3, 4, 6, 7, 8, 9, 10, 11, 19, 20, 23, 24, and 25 showed moderate and significant correlations with the answers of the first interview.

Regarding the first interview, item 22 showed perfect linear correlation $(r=1, p<0.001)$, while item 12 showed a weak correlation with the answers of the first interview, as shown in Table 4. 
Table 4 - Correlation of the scores obtained in the PDI - Br test-retest. São Paulo, SP, Brazil, 2018

\begin{tabular}{|c|c|c|}
\hline \multicolumn{3}{|l|}{ Patient Dignity Inventory, PDI - Br ( $n=32)$} \\
\hline Items & $\mathbf{r}^{*}$ & p† \\
\hline 1. Not being able to perform daily life activities (e.g.: taking a bath, getting dressed). & 0.557 & $<0.001$ \\
\hline 2. Not being able to perform my body functions independently (e.g.: needing help to go to the toilet). & $0.755^{*}$ & $<0.001$ \\
\hline 3. Feeling stressing physical symptoms (e.g.: pain, shortness of breath, nausea). & 0.508 & 0.003 \\
\hline 4. Feeling that, for the others, my appearance changed substantially. & 0.602 & $<0.001$ \\
\hline 5. Feeling depressed. & 0.784 & $<0.001$ \\
\hline 6. Feeling anxious. & 0.643 & $<0.001$ \\
\hline 7. Feeling uncertainty about my disease and the treatment. & 0.611 & $<0.001$ \\
\hline 8. Worrying about my future. & 0.571 & $<0.001$ \\
\hline 9. Not being able to think clearly. & 0.627 & $<0.001$ \\
\hline 10. Not being able to go on with my routine activities. & 0.551 & $<0.001$ \\
\hline 11. Feeling that I am no longer who I was. & 0.663 & $<0.001$ \\
\hline 12. Not feeling useful or valued. & 0.330 & 0.065 \\
\hline 13. Not being able to fulfill important roles (e.g.: wife/husband, father/mother). & 0.803 & $<0.001$ \\
\hline 14. Feeling that life makes no sense or has no purpose any longer. & 0.703 & $<0.001$ \\
\hline 15. Feeling that I have not made any significant and lasting contribution in my life. & 0.771 & $<0.001$ \\
\hline 16. Feeling that I have "unfinished businesses" (e.g.: incomplete or unsaid things). & 0.718 & $<0.001$ \\
\hline 17. Worrying about my spiritual life not being significant. & 0.823 & $<0.001$ \\
\hline 18. Feeling that I am a burden for the others. & 0.709 & $<0.001$ \\
\hline 19. Feeling that I have no control over my own life. & 0.692 & $<0.001$ \\
\hline 20. Feeling that my disease and care needs reduced my privacy. & 0.598 & $<0.001$ \\
\hline 21. Not feeling supported by my group of friends and family. & - & - \\
\hline 22. Not feeling support from the health professionals who care for me. & 1 & $<0.001$ \\
\hline 23. Feeling that I cannot mentally "fight" against the challenges of the disease any longer. & 0.633 & $<0.001$ \\
\hline 24. Not being able to accept things as they are. & 0.694 & $<0.001$ \\
\hline 25. Not being treated with respect or understanding. & 0.641 & $<0.001$ \\
\hline
\end{tabular}

${ }^{*}$ Pearson's correlation coefficient; ${ }^{+}$Significance level, $p<0.001$

The exploratory factor analysis of the PDI - Br showed that all the items were loaded in the data correlation matrix. For the decision to remove or keep the items in the final instrument, the factorial loads were evaluated together with observation of the internal consistency, using the value of Cronbach's a; although items 11, 16 and 17 presented factorial loads below 0.30 ( $F L=0.284$, $\mathrm{FL}=0.277$ and $\mathrm{FL}=0.260$, respectively), they remained in the instrument. Only the removal of item 17 would increase the value of Cronbach's a by 0.003 , an increase considered insignificant. The analysis of the internal consistency in association with the factorial loads is the basis for the composition of the PDI - $\mathrm{Br}$ in 25 items, gathered in 3 domains/factors/dimensions ( 1 1, $A 2$, and $A 3$ ).

In the A1 domain, there are items related to physical and emotional symptoms, so it was named "Presence of Symptoms" (PS), as well as in the Canadian instrument. The $\mathrm{A} 2$ domain received the nomenclature of "Dependence" (D), since its conformation is identical to the Chochinov instrument. The A3 domain was named "Existential Suffering", as it contemplates 3 of the items in the Canadian instrument domain, items 12, 13, and 14 .

Moderate, positive, and significant correlations were noticed between the PS domain and the symptoms of sadness and anxiety, measured by the ESAS and anxiety, as measured by the HADS, in the observation of convergent validity. Among the other symptoms measured by the ESAS and HADS scales and the PDI - Br, the correlations were weak or very weak (Table 5).

For the PDI - Br Dependence (D) and Spiritual Suffering (SS) domains, weak and very weak correlations were found with the scales that measure symptoms. The evaluation of the hypothesis of negative correlation between the PDI - Br domains and the KPS, FACIT-sp 12 and EORTC-QLQ-C30 instruments showed negative and weak associations, as detailed in Table 5. 
Table 5 - Correlation of the Patient Dignity Inventory (PDI - Br) and the ESAS, HADS, Karnofsky, FACIT- sp, and EORTC-QLQ-C30 scales. São Paulo, SP, Brazil, 2018

\begin{tabular}{|c|c|c|c|c|c|c|}
\hline \multirow{3}{*}{$\begin{array}{l}\text { Scales }(n=135) \\
\text { ESAS }\end{array}$} & \multicolumn{6}{|c|}{ Domains (PDI - Br) } \\
\hline & \multicolumn{2}{|c|}{$\mathrm{PS}^{*}$} & \multicolumn{2}{|c|}{$\mathbf{D}^{\dagger}$} & \multicolumn{2}{|c|}{ SS $^{\ddagger}$} \\
\hline & $r^{\S}$ & $\mathbf{p}^{\|}$ & $r^{\S}$ & $\mathbf{p}^{\|}$ & $r^{\S}$ & $\mathbf{p}^{\|}$ \\
\hline Pain & 0.230 & $<0.001$ & 0.280 & $<0.001$ & 0.068 & 0.291 \\
\hline Tiredness & 0.179 & 0.005 & 0.224 & $<0.001$ & 0.132 & 0.038 \\
\hline Nausea & 0.154 & 0.021 & 0.109 & 0.102 & 0.142 & 0.033 \\
\hline Sadness & 0.443 & $<0.001$ & 0.325 & $<0.001$ & 0.253 & $<0.001$ \\
\hline Anxiety & 0.464 & $<0.001$ & 0.242 & $<0.001$ & 0.143 & 0.026 \\
\hline Sleepiness & 0.142 & 0.029 & 0.087 & 0.181 & 0.136 & 0.036 \\
\hline Appetite & 0.010 & 0.882 & 0.005 & 0.935 & 0.043 & 0.514 \\
\hline Well-being & 0.131 & 0.044 & 0.015 & 0.820 & 0.066 & 0.311 \\
\hline Shortness of breath & 0.119 & 0.067 & 0.140 & 0.031 & 0.176 & 0.007 \\
\hline Sleep & 0.146 & 0.022 & 0.078 & 0.221 & 0.032 & 0.614 \\
\hline Total & 0.372 & $<0.001$ & 0.262 & $<0.001$ & 0.223 & $<0.001$ \\
\hline \multicolumn{7}{|l|}{ HADS } \\
\hline Anxiety & 0.430 & $<0.001$ & 0.269 & $<0.001$ & 0.240 & $<0.001$ \\
\hline Depression & 0.336 & $<0.001$ & 0.235 & $<0.001$ & 0.263 & $<0.001$ \\
\hline \multicolumn{7}{|l|}{ Karnofsky (KPS) } \\
\hline & -0.257 & $<0.001$ & -0.291 & $<0.001$ & -0.238 & $<0.001$ \\
\hline \multicolumn{7}{|l|}{ FACIT -sp 12} \\
\hline Meaning and peace & -0.296 & $<0.001$ & -0.127 & 0.036 & -0.361 & $<0.001$ \\
\hline Faith & -0.143 & 0.022 & 0.018 & 0.775 & -0.316 & $<0.001$ \\
\hline Total & -0.254 & $<0.001$ & -0.068 & 0.256 & -0.374 & $<0.001$ \\
\hline \multicolumn{7}{|l|}{ EORTC-QLQ-C30 } \\
\hline General health & -0.202 & 0.001 & -0.149 & 0.018 & -0.206 & 0.001 \\
\hline General quality of life & -0.269 & $<0.001$ & -0.180 & 0.004 & -0.257 & $<0.001$ \\
\hline
\end{tabular}

${ }^{*}$ Presence of symptoms; ${ }^{+}$Dependence; ${ }^{*}$ Spiritual suffering; ${ }^{\text {PPearson' }}$ correlation coefficient; $" \mathrm{p}<0.05$

\section{Discussion}

For psychometric validation studies, the literature suggests samplings over 50 individuals, recommending at least 100 people; these recommendations are necessary to guarantee more solid conclusions, from the mean of 5 or more observations per item ${ }^{(24)} .135$ patients were interviewed in this study, which guaranteed a mean of 5.4 observations for each item of the PDI - Br.

Evidence from the literature also shows that values greater than 0.30 are admissible for factor loads ${ }^{(24)}$. The correlation matrix of the exploratory factor analysis resulted in a three-factor solution for the PDI - $\mathrm{Br}$; in this analysis, items 11, 16, and 17 showed factor loads lower than the recommended ones. However, the 25 items of the instrument were organized only once in each of the three domains.

An Italian study that examined the factorial structure of the PDI applied exploratory factor analysis and also found three factors, with an explained variance of $64.4 \%{ }^{(26)}$, a value which is higher than the one observed in this study (40.9\%). In the Italian research the three factors were named as follows: existential suffering, psychological suffering, and physical suffering(26). In the present study, the three factors were named presence of symptoms, dependence and existential suffering.

The definition for the final organization of an instrument should not be based only on one criterion (24). According to the recommendations in the literature, the following elements were considered for the definition of maintenance or removal of items from the PDI - $\mathrm{Br}$ : factorial loads greater than 0.30 , correlation between the PDI - $\mathrm{Br}$ domains, reliability through internal consistency (Cronbach's a coefficient, recommended values greater than 0.70 ), and assessment of the domain's a value after the removal of each item.

For a population of 135 patients, a Cronbach's a value of 0.90 is greater than the recommended one. This indicates that the items really measure the dignity construct, indicating that there is an interconnection between them ${ }^{(24)}$. 
The values found for Cronbach's a in this study are similar to those evidenced in other PDI validation studies, such as in Canada $\left(n=149\right.$ and $\left.a=0.93^{(11)}\right)$, Germany ( $n=112$ and $\left.a=0.96^{(12)}\right)$, Spain $(n=124$ and $\left.a=0.89^{(13)}\right)$, Italy $\left(n=266\right.$ and $\left.a=0.96^{(14)}\right)$ and Greece $\left(n=120\right.$ and $a=0.71$ to $\left.0.9^{(15)}\right)$.

The values of the Cronbach's a coefficient for the domains were $a=0.859$ ( $A 1), a=0.871$ ( $A 2$ ) and $a=0.759$ (A3), considered above what is acceptable in the literature (reference value $=0.70)^{(24)}$. The data corroborate for a three-factor solution with adequate internal consistency.

In the Canadian instrument, validated in 2008, items 10, 19, 23, and 24 were not loaded in any domain after performing the exploratory factor analysis, but were kept in the instrument, because they were highly related to a loss of sense of dignity, according to the Chochinov's Theory ${ }^{(11)}$. In the PDI - Br all the items were loaded into the data correlation matrix after exploratory factor analysis.

For the test-retest analysis, 32 patients were approached at two different times, with a mean interval of 31 days between consultations. In the validation surveys of the Patient Dignity Inventory (PDI), the retest was performed at different intervals, 24 hours in Canada, 48 hours in Spain, 1 week in Greece, and 2 weeks in Italy(11,13-15).

Evidence from the literature demonstrates that the reliability of the test-retest assessment can change due to approaches taken over very distant periods of time ${ }^{(22,24)}$. This factor may explain the lower correlation of this study, given the 31-day interval.

Palliative care patients have different stages of the disease and may progress in different proportions over the course of a month. Associated with this, there is a decrease in functionality and an increase in the number and intensity of symptoms, which may have interfered with different perceptions of dignity between the first and second approach of patients.

A research study dealt with the theme of dignity under the scrutiny of autonomy and the sense of control in patients in the final stages of an advanced disease, through a systematic review. The studies compiled by the review showed that aspects such as loss of functionality were directly related to the reduction of dignity, as the loss of body control and the development of daily activities represented a great impact for these patients ${ }^{(27)}$.
In this study, positive, moderate, and significant correlations were evidenced for the symptoms of sadness and anxiety measured by ESAS and the PDI - Br, in addition to a positive correlation between the HADS scale and the PDI - Br.

The data found for the correlation of the PDI with the symptoms of anxiety and depression were similar to those evidenced by other studies. The psychometric validation of the Canadian inventory showed a significant correlation between these elements, being moderate with anxiety $(r=0.453, p<0.001)$ and weak with depression $(r=0.374, p<0.001)^{(11)}$. In studies conducted in Germany (anxiety: $r=0.66$, depression: $r=0.58, p<0.001$ ) and Spain (ESAS: $r=0.669$ and HADS: $r=0.788, p<0.001)^{(12-13)}$, the findings were also similar to those found in this research.

A validation study developed in Greece also found moderate and strong positive correlations between some domains of the PDI and the symptoms of anxiety ( $r=0.44$ to $0.71 ; p<0.005)$, and weak to moderate correlations with the symptoms of depression $(r=0.31 \text { to } 0.57 ; p<0.005)^{(15)}$. An Italian study found weak to moderate positive correlations $(r=0.33$ to $0.55 ; p<0.001)$ between the PDI and symptoms of depression(26).

Evidence from the literature corroborates to explain that the loss of dignity is directly related to worse levels of anxiety and depression. A recent systematic review study found that, by raising patients' sense of dignity, the anxiety and depression levels also improved significantly(28).

For the symptoms evaluated by the ESAS scale, positive, weak and significant correlations were found between the symptoms of pain and tiredness, and very weak and few significant correlations between the PDI - $\mathrm{Br}$ and nausea, appetite, well-being, and shortness of breath. The findings are similar to those found in other validation studies conducted in Canada and Germany ${ }^{(11-12)}$ regarding the pain variable, for which the correlation was positive, weak, and significant.

The convergent validity tests also showed negative correlations between the inventory and the KPS, FACITsp 12 and EORTC-QLQ-C30 instruments, deferring the hypothesis established at first. The PDI - Br domains showed a significant although weak correlation with the functionality measured by the KPS. In the investigation carried out in Spain, the findings between the two instruments were the same ${ }^{(13)}$. 
For the FACIT-sp 12 scale, the Meaning/Peace and Faith domains showed weak and significant negative correlations with the PDI - $\mathrm{Br}$ domains. Compared to other validation studies, in Canada the correlation found was negative, weak, and significant between the peace of mind domain of FACIT-sp $12(r=-0.21, p<0.002)$ and the dignity inventory; in Spain, the correlation was moderate and negative $(r=-0.442 ; p=0.008)$, the same as observed in Italy $(r=-0.40 ; p<0.001)^{(11,13-14)}$.

For the items on the EORT-QLQ-C30 scale, weak and significant correlations were found between the domains of the PDI - $\mathrm{Br}$ and the questions of general health and general health quality. In Germany, the same instrument to measure quality of life was used and the correlation found was significantly moderate and negative $(r=-0.42, p<0.001)^{(12)}$.

A research study carried out in 2015 in Spain showed that the sense of dignity was heightened by the application of the dignity therapy, which also brought significant beneficial effects on spiritual wellbeing $(p<0.001)$ and on quality of life $(p=0.011)^{(13)}$. A previous study conducted in Canada in 2002 highlighted a directly proportional relationship between better quality of life rates and a greater sense of dignity(29).

This research corroborates with studies carried out in other countries regarding the connection between the phenomenon of dignity and the questions of anxiety, depression, pain, functionality, spirituality and quality of life. In addition, the psychometric validation data in this study are also similar to other studies of the same nature for PDI - Br.

Evidence shows that reduced samplings influence the value of Pearson's correlation, forcing this coefficient to present a high magnitude to be significant, with values close to 1 . Psychometric research studies of the PDI in larger samples should be encouraged, especially to perform the correlation hypothesis test, researching the strength of correlation between dignity and the variables measured by the other scales ${ }^{(22)}$.

The results obtained by construct validity through exploratory factor analysis, concurrent validity through convergent validity and reliability through the internal consistency and test-retest of the PDI - Br indicate satisfactory psychometric properties for its use as a measurement tool for problems related to loss of dignity.

This study has strengths and limitations, which can be transposed in new investigations. The great aspect highlighted as a strong point is the provision of a valid and reliable instrument to estimate the dignity of patients, especially those in palliative care. On the other hand, its limitation was the fact that the sample includes patients with low schooling and low socioeconomic status, which represents a portion of the population, but the results may be different in other population stratum.

\section{Conclusion}

The tests performed demonstrate evidence of validity and reliability of the PDI - $\mathrm{Br}$ instrument, composed of three domains and 25 items, confirming its psychometric properties for its use in our country. This instrument offers the health professionals the possibility to assess the perception of dignity of patients in palliative care, contributing to the study of this phenomenon in the national context.

\section{References}

1. National Academy of Palliative Care. Handbook of palliative care. $2^{\text {th }}$ ed. Porto Alegre: Sulina; 2012.

2. Kovács MJ. Towards death with dignity in the XXI Century. Rev Bioet. 2014 Feb 10;22(1): 94-104. doi: 10.1590/S1983-80422014000100011.

3. Instituto Brasileiro de Geografia e Estatística. Projeção da população do Brasil e das Unidades da Federação: 2000-2030. [Internet]. Rio de Janeiro: IBGE; 2019 [Acesso 11 abr 2019]. Disponível em: https://www.ibge.gov.br/apps/populacao/projecao/ 4. Instituto Nacional de Câncer José Alencar Gomes da Silva. Estimativa 2020. [Internet]. Rio de Janeiro: INCA; 2019 [Acesso 11 abr 2019]. Disponível em: https://www.inca.gov.br/estimativa

5. Gomes ALZ, Othero MB. Cuidados paliativos. Estud Av. 2016 Dec;30(88):155-66. doi: 10.1590/s010340142016.30880011

6. Breitbart W. Dignity and meaning in supportive care. Palliat Support Care. 2018;16(6):641-2. doi: 10.1017/ S1478951518000998

7. Chochinov HM, Hack T, McClement S, Kristjanson L, Harlos M. Dignity in the terminally ill: a developing empirical model. Soc Sci Med. 2002 Feb;54(3):433-43. doi: 10.1016/S0277-9536(01)00084-3

8. Franco ME, Salvetti MG, Donato SCT, Carvalho RTD, Franck EM. Perception of dignity of patients in palliative care. Texto Contexto Enferm. 2019;28:e20180142. doi: 10.1590/1980-265x-tce-2018-0142

9. Juliao M, Oliveira F, Nunes B, Vaz Carneiro A, Barbosa A. Efficacy of dignity therapy on depression 
and anxiety in Portuguese terminally ill patients: a phase II randomized controlled trial. J Palliat Med. 2014 Dec;17(6):688-95. doi: 10.1089/jpm.2013.0567

10. Chochinov HM, Kristjanson LJ, Hack T, Hassard T, Mcclement S, Harlos M. Dignity in the terminally ill: revisited. J Palliat Med. 2006 Jun;9(3):666-72. doi: 10.1089/jpm.2006.9.666

11. Chochinov HM, Hassard T, McClement S, Hack T, Kristjanson LJ, Harlos M, et al. The patient dignity inventory: a novel way of measuring dignity-related distress in palliative care. J Pain Symptom Manage. 2008 Dec;36(6):559-71. doi: 10.1016/j.jpainsymman.2007 12. Sautier L, Vehling S, Mehnert A. Assessment of patient's dignity in cancer care: preliminary psychometrics of the German version of the patient dignity inventory (PDI-G). J Pain Symptom Manage. 2014 Jan;47(1):181-8. doi: 10.1016/j. jpainsymman.2013.02.023

13. Rullán M, Carvajal A, Núñez-Córdoba JM, Martínez M, Carrasco JM, García I, et al. Spanish Version of the Patient Dignity Inventory: Translation and Validation in Patients With Advanced Cancer. J Pain Symptom Manage. 2015 Dec;50(6):874-81. doi: 10.1016/j. jpainsymman.2015.07.016

14. Ripamonti CI, Buonaccorso L, Maruelli A. Patient dignity inventory (PDI) questionnaire: the validation study in Italian patients with solid and hematological cancers on active oncological treatments. Tumori. 2012 Aug;98(4):491-500. doi: 10.1700/1146.12645

15. Parpa E, Kostopoulou S, Tsilika E, Galanos A, Katsaragakis S, Mystakidou K. Psychometric properties of the Greek version of the patient dignity inventory in advanced cancer patients. J Pain Symptom Manage. 2017;54(3):376-382. doi: https://doi.org/10.1016/j. jpainsymman.2017.07.002

16. Marcolino JAM, Mathias LAST, Piccinini FL, Guaratini AA, Suzuki FM, Alli LAC. Hospital Anxiety and Depression Scale: A Study on the Validation of the Criteria and Reliability on Preoperative Patients. Rev Bras Anestesiol. 2007 Feb;57(1):52-62. doi: 10.1590/ S0034-70942007000100006.

17. Monteiro DR, Almeida MA, Kruse MHL. Translation and cross-cultural adaptation of the Edmonton Symptom Assessment System for use in Palliative Care. Rev Gaúcha Enferm. 2013;34(2)163-71. doi: 10.1590/ S1983-14472013000200021

18. Campos JADB, Spexoto MCB, Silva WRD, Serrano SV, Marôco J. European Organization for Research and Treatment of Cancer Quality of Life
Questionnaire Core 30: factorial models to Brazilian cancer patients Einstein (São Paulo). [Internet]. 2018 [cited Apr 15, 2020];2018;16(1):eAO4132. Available from: http://www.scielo.br/scielo.php?script $=$ sci_ arttext\&pid=S1679-45082018000100211\&Ing=en

19. Lucchetti GL, Lucchetti AL, de Bernardin GJP, Vallada HP. Validation of the Portuguese version of the Functional Assessment of Chronic Illness Therapy-Spiritual WellBeing scale (FACIT-Sp 12) among Brazilian psychiatric inpatients. J Relig Health. 2015 Feb;54(1):112-21. doi: 10.1007/s10943-013-9785-z

20. Cabianca CÁM, Menegheti GG, Bernardi ICP, Gurgel SJT. Comparação entre Escala de Performance de Karnofsky e Escala de Avaliação de Sintomas de Edmonton como determinantes na assistência paliativa. Rev Soc Bras Clín Méd. [Internet]. 2017 [Acesso 15 abr 2020];15(1):2-5. Available from: http://www.sbcm.org. br/ojs3/index.php/rsbcm/article/view/239/227

21. Beaton DE, Bombardier C, Guillemin F, Ferraz, MB. Guidelines for the process of cross-cultural adaptation of self-report measures. Spine. 2000 Dec;25(24):318691. doi: 10.1097/00007632-200012150-00014

22. Souza AC, Alexandre NMC, Guirardello EB. Psychometric properties in instruments evaluation of reliability and validity. Epidemiol Serv Saúde. 2017 Jul;26(3):649-59. doi: 10.5123/s167949742017000300022

23. Cunha, CM, Almeida Neto OP, Stackfleth R. Principais métodos de avaliação psicométrica da validade de instrumentos de medida. Aten Saúde. 2016 Jan;14(47):75-83. doi: 10.13037/rbcs.vol14n47.3391 24. Hair JF, Black WC, Babin BJ, Anderson RE, Tatham RL. Multivariate Data Analysis. $6^{\text {th }}$ ed. Porto Alegre: Bookman; 2009.

25. Barbetta DC, Assis MR. The Functional Independence Measures (FIM) reliability, validity and responsiveness in spinal cord injury literature review. Acta Fisiátr. [Internet]. 2008 Set [cited Nov 25, 2019];15(3):176181. Available from: http://www.revistas.usp.br/ actafisiatrica/article/view/102946/101250

26. Grassi L, Costantini A, Caruso R, Brunetti S, Marchetti P, Sabato S, et al. Dignity and PsychosocialRelated variables in advanced and nonadvanced cancer patients by using the patient dignity Inventory-Italian version. J Pain Symptom Manage. 2017;53(2):279-87. doi: 10.1016/j.jpainsymman.2016.09.009

27. Rez-Prat A, Monforte-Royo CPSJ. Patient Perspectives of Dignity, Autonomy and Controlat the End of Life: Systematic Review and Meta Ethnography. 
PLoS One. 2016 Mar;11(3):e0151435. doi: 10.1371/ journal.pone.0151435

28. Donato SCT, Matuoka JY, Yamashita CC, Salvetti MG. Effects of dignity therapy on terminally ill patients: a systematic review. Rev Esc Enferm USP. 2016 Dec;50(6):1011-21. doi: 10.1590/s0080623420160000700019

29. Chochinov HM, Hack T, Hassard T, Kristjanson LJ, McClement S, Harlos M. Dignity in the terminally ill: a cross-sectional, cohort study. Lancet. 2002 Dec; 60(9350):2026-30. doi: 10.1016/S0140$6736(02) 12022-8$ Creative Commons (CC BY).

This license lets others distribute, remix, tweak, and build upon your work, even commercially, as long as they credit you for the original creation. This is the most accommodating of licenses offered. Recommended for maximum dissemination and use of licensed materials. 